\title{
O "IMPERATIVO DA APLICAÇÃO" NA FORMAÇÃO DE PROFESSORES DE LÍNGUAS: UMA DISCUSSÃO SOBRE PSICANÁLISE E UNIVERSIDADE
}

\author{
THE "IMPERATIVE OF APPLICATION" IN THE EDUCATION \\ OF LANGUAGE TEACHERS: A DISCUSSION ABOUT PSYCHO- \\ ANALYSIS AND UNIVERSITY
}

\section{Newton Freire Murce Filho* **}

\section{RESUMO}

O objetivo deste artigo é discutir o papel dos estudos da linguagem que levam em conta uma perspectiva psicanalítica nas vertentes freudiana e lacaniana dentro da Universidade. Para isso, a formação de professores de línguas é examinada com foco em dois problemas principais: a desconsideração da importância da linguagem na constituição do sujeito e a dicotomia entre teoria e prática. Partindo de uma experiência docente vivida pelo próprio pesquisador, esta investigação, de natureza bibliográfica, apoia-se em estudos que discutem a complexidade da questão da aprendizagem de língua estrangeira, a relação entre língua materna e língua estrangeira, o papel da linguagem na constituição do sujeito e a relação entre teoria e prática no campo da formação de professores de línguas. O estudo sugere que, na Universidade, aparentemente se desconsidera a complexidade e a importância dessas questões apontadas por uma perspectiva psicanalítica, e que, na relação entre teoria e prática no campo da formação de professores de línguas, destaca-se a primazia da segunda em relação à primeira, o que conduz ao que se chama de o "imperativo da aplicação".

Palavras-chave: formação de professores; psicanálise; Universidade; teoria-prática.

\section{ABSTRACT}

This paper discusses the role of language studies which take into account a Freudian and Lacanian psychoanalytic perspective within the University. To do so, the education of language teachers is examined with a focus on two particular problems: disregard for the importance of language in the constitution of the subject and the dichotomy between theory and practice. Starting from the researcher's own teaching experience, this bibliographical study is supported by earlier works which discuss the complexity involved in foreign language learning, the relationship between mother tongue and foreign language, the role of

\footnotetext{
* UFG, Goiânia (GO), Brasil. newtonmurce@yahoo.com.br

** Esclareço que não ignoro os estudos de diversos pesquisadores que refutam essa aplicabilidade. É o caso, por exemplo, dos autores que contribuíram, com suas reflexões sobre LA, com a proposta do livro de Moita Lopes (2006), Por uma Linguística Aplicada indisciplinar (ver referências).
} 
language in the constitution of the subject and the relationship between theory and practice in the language teacher education field. The study would suggest that the complexity and importance of these issues, highlighted by a psychoanalytical perspective, are disregarded at the University. As far as the relationship between theory and practice in the language teacher education field is concerned, emphasis is given to the latter, which leads to what is called "the imperative of application".

Keywords: education of teachers; Psychoanalysis; University; theory-practice.

Sabe-se que boa parte dos estudos linguísticos necessita, para definir seu objeto, da exclusão da fala e consequentemente, do falante. No entanto, esse falante retorna, não somente nas subáreas da Linguística - como na sociolinguística, na psicolinguística, na pragmática, no funcionalismo, entre outras -, mas também na Linguística Aplicada, cuja vocação interdisciplinar leva o pesquisador a dialogar com formas de conhecimento que consideram o falante, suas visões de mundo e seus valores.

Recentemente, trabalhei como professor em um curso de Especialização em Linguística Aplicada, de uma Universidade Federal, e a discussão que proponho, levando em conta a possibilidade de privilegiar o compromisso com a prática (cf. RAJAGOPALAN, 2006), é efeito de reflexões sobre essa experiência. No referido curso, ministrei a disciplina "Linguagem e Subjetividade", cujo objetivo principal consistia em oferecer ao estudante-professor uma introdução aos estudos da linguagem em sua referência à atividade linguística como prática social, como propõe Rajagopalan (2006, p. 163), mas tendo como foco a constituição do sujeito (aluno e professor) à luz de uma perspectiva psicanalítica, nas vertentes ${ }^{1}$ de Freud e de Lacan. $\mathrm{O}$ conteúdo estudado girou em torno de leituras e discussões sobre os seguintes temas: a) linguagem, corpo e constituição do sujeito; b) o processo ensinoaprendizagem, linguagem e subjetividade $;$ c) língua materna e língua estrangeira; d) linguagem, arte e constituição do sujeito.

Ao final do trabalho, cumprindo uma exigência do curso de Especialização em relação a todas as disciplinas ofertadas, os estudantes-professores deveriam preencher um formulário de avaliação a respeito de cada uma delas e de seus respectivos professores. A discussão que ora levanto tem como base o modo como pude ler as avaliações de alguns dos estudantes-professores que frequentaram a disciplina que ofereci. Surpreendeu-me a leitura de alguns comentários de que a disciplina não tinha relação com a prática dos estudantes-professores, com seu cotidiano em sala de aula. O que se contestava, de fato - mesmo que essa

1 Além das obras de Freud $(1905 ;$ 1929) e de Lacan $(2005)$, todos os autores que tematizam a psicanálise e estão citados em minhas referências filiam-se a essas vertentes. 
'reclamação' tenha aparecido em uma pequena parte das avaliações -, era se teria sido muito útil ter frequentado o curso.

Não tomo como objeto de análise neste trabalho as avaliações propriamente ditas $^{2}$, uma vez que não havia previsto que faria este estudo no início do curso e, consequentemente, não teria tido como pedir autorização para publicá-las ou analisá-las. O que importa para a presente reflexão, no entanto, e que tomo como elementos para discussão e análise, são os efeitos da leitura dessas avaliações sobre mim, seja como professor de língua inglesa, como professor na área de formação de professores de línguas e como estudioso de Psicanálise. Em outras palavras, importa analisar os efeitos da leitura dessas avaliações - que em nenhum momento contestaram algo como falta de preparo das aulas ou um não domínio do conteúdo - em meu fazer-dizer, o modo como pude me subjetivar diante da avaliação de minha prática por parte daqueles estudantes-professores naquele contexto de ensino. Para este objetivo é suficiente dizer então que aquilo que se destaca em algumas avaliações que me chamaram a atenção e que me convocaram a fazer estas reflexões consiste no que pode ser resumido da seguinte maneira: a disciplina oferecida não apresenta relações com a prática cotidiana escolar, não bá aplicabilidade ao ensino de línguas, consequentemente, não foi muito útil frequentá-la. No momento da leitura dessas avaliações, veio-me à mente a constatação de Freud (1929/1996, p.101, grifo meu), em "O mal-estar na civilização", de que "a força motivadora de todas as atividades humanas é um esforço desenvolvido no sentido de duas metas confluentes, a de utilidade e a de obtenção de prazer", bem como minha experiência com professores de LE, em que pude muitas vezes observar esse esforço em mostrar a utilidade, a aplicabilidade, que, neste trabalho, acaba resultando no que chamo de "imperativo" da aplicação.

Partindo de minha surpresa e de minha preocupação diante da leitura de algumas avaliações, proponho como foco para orientar a discussão dois pontos que, a meu ver, são fundamentais para examinar a questão da formação de professores e o trabalho destes com alunos de línguas: a) o problema da desconsideração da determinação e da importância da linguagem na constituição do sujeito e na constituição das subjetividades daqueles que estudam ou que ensinam línguas; e b) o problema da dicotomia entre teoria e prática e da supervalorização desta em detrimento da primeira. Trata-se, portanto, de um estudo de natureza investigativa em que pretendo problematizar esses dois pontos destacados, partindo de minha

\footnotetext{
2 No final do curso os alunos receberam uma ficha de avaliação com perguntas do tipo: as aulas ministradas foram bem preparadas? O conteúdo foi explicado pelo(a) docente com domínio? As técnicas de ensino foram bem selecionadas e empregadas? Os critérios de avaliação foram previamente esclarecidos e seguidos nas avaliações?
} 
experiência como professor-pesquisador, de publicações a respeito dessas questões e do modo como pude me subjetivar diante da avaliação de minha prática.

Metodologicamente, farei uma apresentação nos moldes de uma pesquisa bibliográfica, iniciando com um breve relato e comentários acerca de trabalhos já publicados, de uma perspectiva psicanalítica, particularmente freudianas e/ou lacanianas, e que dão um suporte teórico à discussão; falo dos trabalhos de Revuz (1998), Moraes (1999, 2009), Lemos (2007), Freire e Murce (2009). A partir da leitura desses trabalhos é que busco chegar a alguma compreensão do papel dos estudos da linguagem que levam em conta a Psicanálise na Universidade e que consideram especialmente a formação de professores, o ensino-aprendizagem de línguas e o mal-estar, no incômodo e no desconforto que a Psicanálise parece provocar. Importa ressaltar que o fato de as avaliações terem sido feitas ao final do curso, e a mim entregues em época em que já não havia a possibilidade de discutir esse mal-estar com os estudantes-professores, produziu algo de positivo: o malestar que me leva a refletir sobre a experiência vivida por mim, como professor da disciplina.

No que diz respeito à dicotomia teoria e prática, o maior desafio neste trabalho é levar adiante esta autorreflexão pensando com (e mesmo contra) os trabalhos teóricos de que parto e que fazem leituras interessantes de certos pressupostos da área de ensino de LE e do campo da LA. Em sua pesquisa sobre formação contínua de professores, Duarte (2011) constata que a atual fundamentação para a formação docente se insere na perspectiva da epistemologia da prática, que propõe uma formação que opera de modo prescritivo, determinando seja a ação dos professores no momento de refletir sobre sua prática, seja o tipo de investigação a adotar e a intervenção de um pesquisador com reconhecido domínio do conhecimento, numa visão praticista e tecnicista. É como se tudo o que se estuda tivesse que ter algum tipo de aplicação, alguma utilidade, especialmente para a sala de aula ${ }^{3}$. Esse imperativo determina o campo de formação de professores de tal forma que acaba não havendo, evidentemente, espaço para uma reflexão sobre o sujeito, por exemplo. Muito menos sobre o sujeito da Psicanálise. E menos ainda se esse sujeito é tomado

3 É importante destacar que há professores mais ou menos preocupados com o cumprimento do conteúdo programático e que o ensino de LE ainda carrega fortes marcas de sua história de discussões com respeito, por exemplo, à questão forma $v$ s uso da LE, gerando ainda discussões sobre ensinar/não ensinar e como ensinar gramática em LE - ponto problematizado detalhadamente por Schmitz (2007), que discute a polarização (ensinar/não ensinar gramática de LE) e encerra seu trabalho advogando em favor do enfoque no uso da língua e não na forma, defendendo o ensino de gramática para alunos que "procuram estudar gramática para se sentirem mais confiantes no seu desempenho' (p. 158). Observo que encontro aqui um ponto que se poderia considerar uma forma de tratar a subjetividade do aluno. 
em sua radicalidade, tal como esclarece Porge (2009) no texto "Um sujeito sem subjetividade", com o qual busco dialogar algumas páginas adiante.

\section{UMA PERSPECTIVA PSICANALÍTICA}

No que concerne ao problema da desconsideração da determinação e da importância da linguagem na constituição do sujeito e na constituição das subjetividades daqueles que estudam ou que ensinam línguas, convém trazer algumas contribuições significativas, de uma perspectiva psicanalítica no próprio campo da LA, e que foram discutidas durante o curso de Especialização em questão. Uma delas é a de que a aprendizagem de uma língua estrangeira não é, definitivamente, um processo sem complicações, uma vez que ela solicita, ao mesmo tempo, três dimensões, conforme atesta Revuz (1998, p. 216-217): a do eu, em sua ilusão de autoconhecimento, o trabalho do corpo e a dimensão cognitiva - que diz respeito aqui à existência de um momento de memorização na aprendizagem de LE. Como prática corporal, a língua estrangeira (LE) põe em jogo todo o aparelho fonador, fazendo que o sujeito tenha que colocar a serviço da expressão de seu eu um vaivém que requer muita flexibilidade psíquica entre um trabalho de corpo sobre e sob os ritmos, os sons, as curvas entoacionais, bem como um trabalho de análise e de memorização das estruturas linguísticas. Além disso, continua a autora, a LE solicita as bases de nossa estruturação psíquica e aquilo que é, ao mesmo tempo, o instrumento e a matéria dessa estruturação, que é a língua materna que teceu nosso inconsciente. Aprender uma LE, portanto, significa necessariamente "perturbar, questionar, modificar aquilo que está inscrito em nós com as palavras dessa primeira língua" (REVUZ, 1998, p.217). Por outro lado, se, como a própria autora (REVUZ, 1998, p.227) afirma, "aprender uma língua é sempre, um pouco, tornar-se um outro", esse tornar-se outro não pode estar na dependência de um eu constituído, fechado e acabado, mas de um eu que não é nunca um eu mesmo, e sim um eu em devir - nesse caso, sempre se tornando/tornado outro, marcado pela alteridade que a LE vai tirar dos bastidores e pôr em cena como eu em desconhecimento e sujeito sem subjetividade, no sentido proposto por Porge (2009). Essa constatação pode não ter utilidade prática, porém não é sem consequências.

A língua materna, por sua vez, não é "adquirida" naturalmente, sem sofrimento. O infans, ou seja, aquele que ainda não fala, para tornar-se falante, tem que se submeter ao outro - que lhe fala e por quem é falado, o outro materno - e ao Outro, que é o campo do simbólico, sendo forçado a perder o prazer de brincar 
com as palavras, com seus sons, ritmos e rimas, "até que só restam permitidas as combinações significativas de palavras" (Freud, 1905/1996, p.122). Só assim, submetido ao Outro, ao campo da linguagem, o infans torna-se sujeito. A língua é, pois, o material fundador de nosso psiquismo e de nossa vida relacional, ela não é, portanto, mero instrumento de comunicação, mas causa de sujeito. Essa elaboração, certamente, exige reflexão e pode mesmo não ter aplicação direta, porém, não significa pouca coisa. Nas palavras de Revuz (1998, p.219):

a descoberta das palavras, das significações linguísticas é indissociável da experiência da relação com o outro e das significações libidinais que se inscrevem nela. A voz, as palavras da mãe são fontes de prazer ou de desprazer; elas têm, além disso, o poder de interferir nas outras sensações (visão, tato, paladar) reforçando ou anulando os sentimentos de prazer ou de desgosto que são ligados a elas.

A aprendizagem de LE, ao convocar a materialidade linguística que teceu nosso inconsciente e que comporta sensações de agrado ou de desagrado, atualiza uma experiência esquecida que está aquém de nossa constituição como sujeitos. Trazer para os professores do curso essa discussão significava, para mim, chamar sua atenção para o fato de que o corpo do aprendiz de uma LE é convocado e remetido a esse tempo em que ainda prescinde dos sentidos. Falo do tempo do corpo que brinca, que goza com a sonoridade e a plasticidade das palavras. Ao aprender uma LE, em sala de aula, por exemplo, esse aprendiz vai encontrar o não-familiar, a sequência sonora que não faz sentido, os sons que não consegue reproduzir e, nesse encontro, seu corpo pode passar por reações como rubor, riso, suor, tremor, gagueira etc., uma vez que, desprovido da máscara dos sentidos, fica exposto de forma constrangedora (FREIRE e MURCE, 2009, p.80).

Ainda sobre a complexidade da relação entre língua materna e língua estrangeira, os estudos em Psicanálise trazem avanços importantes. Veras (2008, p.118) lembra, por exemplo, com Bergès e Balbo (2002), que todos somos bilíngues "porque falamos uma língua que tem nela (esquecida) uma outra, uma reserva, uma estrangeiridade, algo que nos é alheio, que foi recalcado nessa língua materna primeira, e que nos faz desejar". Quanto à LE, a autora sugere que "sua aprendizagem exige mediações pedagógicas e técnicas, e pode se esgotar em um uso estritamente instrumental (tradução, comunicação, leitura)". Outra constatação relevante da autora concerne a problemas que resultam da difícil correspondência entre o que a escola idealiza e os sujeitos que a compõem: "o ideal de homogeneidade que marca o cotidiano escolar não permite que se considere cada criança em sua singularidade, levando em conta seu desejo, e acaba por produzir sintomas (fracasso escolar, problemas no aprendizado, exclusão)" (VERAS, 2008, p.111). 
Moraes (1999) tem um importante trabalho sobre a relação nada evidente entre língua materna e língua estrangeira, no qual expõe, com base na hipótese freudiana do inconsciente e partindo do estranhamento próprio da língua materna, a perda do estatuto de 'estranha', por parte da LE. Em um texto recente, a pesquisadora (MORAES, 2009, p.65-66) avança em sua discussão sobre a diferença "natural" que se estabelece como fronteira entre o familiar e o estrangeiro, que são colocados em lados opostos ou mesmo antagônicos, interrogando os estatutos de familiar, atribuído à língua materna, e de estranho, à língua estrangeira. A autora toma, "na representação do estranho, o elemento organizador, e não diferenciador, nessa relação entre línguas" e continua afirmando que "[é] através dessa representação que se dá a passagem entre línguas" (2009, p.65-66). Se elaborações como essas não têm utilidade prática, ao menos nos convocam a pensar a complexidade constitutiva de nossas posições como professor e como aprendiz de línguas.

Antes de terminar esta primeira parte do trabalho, vale a pena trazer uma contribuição de Lemos (2007, p.87) sobre a relação professor-aluno, que aponta para uma via desejante no ato educativo. Essa pesquisadora expõe o problema de a autoridade simbólica do professor ser questionada na medida em que o aluno é hoje visto como consumidor ou usuário. Nesse contexto, ela se pergunta: "quando é que o ato educativo pode engajar o aluno numa via desejante?" E responde: "Isso pode acontecer quando o desejo do professor está dirigido a Outro lugar, para fora da própria cena educativa" (LEMOS, 2007, p.87, grifos da autora), e nesse momento ele realizaria a função de interditar, que não estaria no poder de, por exemplo, reprovar o aluno, mas no despertar de um desejo causado mais pela língua inglesa, que o professor ensina, do que pela necessidade de "reencontrar no aluno os sinais de confirmação de que sua mensagem foi recebida sem deformações" (LEMOS, 2007, p.87).

Os breves relatos dessas pesquisas em Psicanálise que tratam da constituição do sujeito por linguagem, da relação entre língua materna e língua estrangeira e do ensino e da aprendizagem de línguas são fundamentais em um curso que pretende justamente refletir sobre a importância de considerar que essas questões não são simples e que precisam ser discutidas. Foi o que se tentou fazer ao longo do curso de Especialização a que me refiro neste trabalho. No entanto, em algumas declarações de estudantes-professores do curso, aparece o comentário de que tais temas não têm relação com a sua realidade de professores e de seus alunos. Como se cada um deles, ou melhor, cada um de nós que somos professores ou alunos de línguas não houvesse passado por um ou outro tipo de experiência com a própria língua materna ou com línguas estrangeiras que, em algum momento, nos tivesse 
regozijado, machucado, envergonhado, extasiado, magoado ou mesmo excitado. Como se cada um de nós pudesse ser, em algum momento, desprovido de corpo, naquilo que o corpo comporta de zonas erógenas, libidinais, ou naquilo que o corpo comporta de marcas, por vezes traumáticas, que o constituem como tal. Como se o corpo de cada um de nós fosse desprovido de afetos, como se fosse apenas do registro do simbólico e do imaginário, como se não houvesse o irrepresentável, o indizível que marca o corpo. Em determinadas concepções de professores sobre ensino de LE, que supervalorizam o imperativo da aplicação, este é o corpo de que se trata: um corpo sem afetos.

\section{A DICOTOMIA 'TEORIA E PRÁTICA'}

Em se tratando do problema da dicotomia teoria e prática, remeto outra vez ao texto de Duarte (2011, p.100-101), que afirma em sua pesquisa que os professores formadores de professores em LA destacam a importância da teoria na formação contínua de professores. No entanto, segundo observa a autora, a teorização deve partir de uma reflexão sobre a prática, a fim de que mudanças sejam efetivadas, o professor sendo assim capaz de contribuir para a transformação das injustiças e desigualdades sociais. O modo de operação desse ideal, dessa aplicação, seria a prática reflexivo-crítica, que levaria à compreensão da ação, por meio, fundamentalmente, de pesquisas colaborativas. É interessante trazer neste ponto o que parece constituir um exemplo disso. Trata-se de um excerto da apresentação dos princípios de um Núcleo de Assessoria Pedagógica de uma Universidade brasileira que trabalha com formação de professores:

\footnotetext{
pensamos que uma formação que pretende atingir e transformar a educação deve acontecer de maneira colaborativa, levando os professores a desenvolverem uma cultura de trabalhar em conjunto para aprender em conjunto com seus pares, sem perder de vista seu local de trabalbo e sua realidade de ensino (JORDÃO et.al. 2011, p.7, grifos meus).
}

Para dialogar com o trabalho de Duarte, é oportuno o trabalho de Nogueira e Fiad (2007). Com o foco dirigido à formação do professor e à relação entre teoria e prática na constituição do saber docente, as pesquisadoras analisam dados obtidos em reuniões com um grupo de estudo de uma escola municipal, e mostram, a partir das falas de professores participantes, que o que se reitera é a necessidade de "aprender para compreender e lidar com as situações escolares", e de 'teorias' que deem conta "[...] daquilo que escapa" (p. 303). Em suas palavras finais, as pesquisadoras constatam que o "movimento de apropriação [do conhecimento 
teórico] não se configura como fator determinante do trabalho do professor" e que "[...] se constituem contextualizados em determinadas práticas educativas institucionais e históricas" (p. 312).

Como se pode observar, o discurso da aplicabilidade é marcado por uma necessidade de completude, configurando o seguinte imperativo: não pode haver falta - conforme se lê no trecho acima (com relação à utilidade das teorias) e como enfatiza Lemos, no trabalho citado. É preciso levar os professores a atingir determinado objetivo, em conjunto e, mais importante: "sem perder de vista seu local de trabalho e sua realidade de ensino", ou "as práticas educativas institucionais e históricas"; ou seja, nesses discursos não parece haver espaço para a falta. Ora, dentro de um universo como esse em que não pode haver falta, o que resta, senão a falta da falta? E o que é a falta da falta senão a angústia, tal como Lacan (19621963/2005) elabora, no Seminário 10?

Como é conhecimento de todos que trabalham com ensino, e talvez especialmente com ensino de línguas, a sensação de angústia é constante e manifestada por meio de contínuas queixas, frustrações, mágoas e os mais diversos sintomas. A esse universo, os professores acabam tornando-se "adaptados", quase paralisados, conformados. Não se pode deixar de observar, evidentemente, que essa conformidade vai ao encontro do que é próprio do discurso da ciência, que se apresenta predominantemente como um bloco fechado, muitas vezes hegemônico e que almeja a completude, a utilidade, a neutralidade, a aplicabilidade, evitando assim o furo e a falta. Então, quando se deparam com um discurso outro, que desloca o imaginário desses professores, colocando-os diante do fato de que o que há é a falta - e é justamente o que a Psicanálise revela: que há incompletude, que há a falta -, estranham, assustam-se e resistem. Há um mal-estar que é, em grande parte, efeito da impossibilidade de haver completude, tão almejada no discurso da ciência e, evidentemente, no discurso predominante da LA e no discurso de professores e de alunos. No caso da minha experiência recente, alguns estudantesprofessores resistiram ao curso que ofereci sobre Psicanálise, fazendo observações de que a disciplina não tinha grandes conexões com a realidade em que atuam, não tinha, enfim, aplicação. Faltaram meios de aplicação, segundo eles. Sob os efeitos das prescrições trazidas do campo da Educação, os alunos se indagam sobre para que serve uma disciplina de LA se não for para aplicar algo na prática, "no meu local de trabalho, na minha realidade de ensino"? Não pode faltar algo. Porém, esquecese que há um preço a pagar: se há falta da falta, há angústiaª .

4 Sobre a dimensão da angústia no campo da pedagogia, Azenha (2006) tem um trabalho relevante no qual ela mostra que a pedagogia, tal como se observa em muitos trabalhos da LA, faz apelo ao conhecimento científico na busca de um sujeito a quem nada falte, o que produz como efeito a angústia. 


\section{0 LUGAR DE QUE SE FALA}

Tal como traz o trabalho de Duarte (2011, p. 101), a teoria que importa é a que está imediatamente relacionada à prática: "uma instrumentalização da teoria cujo objetivo é a solução de problemas, limitando, portanto, a chance de o professor tornar-se autônomo e crítico" ${ }^{\prime 6}$. Muito provavelmente sem ter consciência disso, Duarte (2011) está também enredada pelo discurso corrente, a partir do qual fala, uma vez que, sendo professora e pesquisadora de línguas, esse enredamento a faz desejar, ou pelo menos aponta para um desejo comum em sua área e em sua perspectiva teórica: o de que o professor torne-se autônomo e crítico. Considerando o lugar a partir do qual se posiciona, não poderia ser de outra maneira, ou seja, essa pesquisadora também, de algum modo, almeja certa aplicabilidade que seria a consideração da teoria não apenas como instrumento para solução de problemas na prática, visto que "nem toda teoria precisa estar relacionada imediatamente à prática", mas como "instância de mediação na compreensão dos processos implicados" (DUARTE, 2011, p. 101), o que contribuiria para a formação de um professor autônomo e crítico.

O que essa pesquisadora esquece, assim como todos nós esquecemos, é que por mais que alguém se almeje um professor autônomo e crítico, o que insiste sempre e que está para além dessa posição subjetiva circunscrita fortemente pelo imaginário, o que há é que, além dessa posição de professor, de linguista aplicado ou de aluno, há sempre um sujeito. Um sujeito sem subjetividade. O que significa isso? Retomando Lacan, Porge (2009, p.152) lembra que o sujeito da Psicanálise "não tem subjetividade, ele se institui na sua destituição" [...], porque ele é apenas representado de um significante para outro significante, sendo sempre outro. Onde há sujeito há fading [desaparecimento] da subjetividade. Nesse espaço-tempo entre dois significantes ele é foracluído, signo de nada, pura hipótese". Ainda segundo o psicanalista (PORGE, 2009, p.155), "o ser do sujeito não é a subjetividade, é seu excremento", e fazer coincidir sujeitos e subjetividades com as determinações sociais, que são muito gerais e imprecisas, traz como consequência o esquecimento da fala singular: "ali onde os sujeitos são identificados de fora, eles são fixados em uma identificação que faz identidade".

Se o sujeito é entendido em sua radicalidade, sem subjetividade, ele então não tem lugar na Universidade, ele é o sujeito da Psicanálise, considerada tão somente em sua ligação com a clínica. No entanto, esse sujeito está na Universidade. Ele é aluno, é professor, pesquisador, portanto, ocupa um lugar ali e tem que ser levado em conta o fato de que é sujeito. Mas como levar em conta o que é pura hipótese, 
evanescência, um instante que cai no momento em que irrompe? Para que serve esse sujeito que não é nada além de evanescência? Não serve pra nada. Não serve. Ele não é servo. Ele não é nada. Ele não está a serviço da ciência, muito menos de sua aplicação. Porque ele sempre escapa dela. Ele é efeito. Afetos. Efeitos.

Talvez uma das respostas possíveis à pergunta sobre como levar em conta o lugar do sujeito da Psicanálise na Universidade esteja na admissão de que esse sujeito tem um corpo. Não apenas um corpo biológico, mas um corpo pulsional, erógeno e que comporta o campo do irrepresentável, do impossível de dizer, que Lacan denominou Real (LACAN, 1974-1975), e que, por isso mesmo, tem poder criativo.

\section{FALANDO EM AVALIAÇÃO...}

Para terminar, um breve relato e uma última reflexão sobre os efeitos da leitura de algumas daquelas avaliações dos alunos sobre o curso oferecido por mim. Ao final do semestre, em reunião com a coordenação, o corpo docente do curso e representantes dos estudantes-professores, comuniquei que não daria mais a disciplina "Linguagem e Subjetividade", e até sugeri que ela fosse retirada do currículo. A decisão foi tomada não sem hesitação e reflexão de minha parte, e confesso que outros fatores determinantes a influenciaram: o fato de se tratar de um curso pago (não público), o fato de eu discordar do modo como o curso é coordenado e avaliado. Porém, ainda que sozinho para oferecer o curso, ao menos naquele momento, naquela Universidade, penso que deveria ter havido maior resistência de minha parte em relação a uma luta para garantir, sim, mais espaço para a Psicanálise na Universidade. Ainda bem que isso será possível, em outro curso a ser iniciado em breve - agora no mestrado, com outros moldes.

Só é possível problematizar a nossa prática se, a partir dela, pudermos questionar os pressupostos teóricos que a embasam. É somente a partir dessa posição, com ela e contra ela, que pude refletir sobre minha prática. Sobre a questão do imperativo da aplicação, não posso deixar de reconhecer, portanto, que, assim como todo professor de línguas ou formador de professores de línguas, não tenho como não ser afetado por esse discurso e, de uma posição subjetiva como esta, reconheço que, bem lá no fundo, claro, eu queria que meu curso tivesse servido para alguma coisa, se não para mobilizar os estudantes-professores de alguma forma, ao menos para ser um pouco amado. 


\section{REFERÊNCIAS BIBLIOGRÁFICAS}

AZENHA, C. (2006). Lia: do nome ao verbo. Dissertação de mestrado em Linguística. Instituto de Estudos da Linguagem, Unicamp, Campinas.

BERGÉS J.; BALBO, G. (2002). Jogo de posições da mãe e da criança: ensaio sobre o transitivismo, trad. Ângela Vorcaro, Nina Virgínia de Araújo Leite e Viviane Veras. Porto Alegre: CMC Editora.

DUARTE, M. S. (2011). Formação contínua de professores de língua inglesa no Brasil: a prática reflexiva crítica em questão. Tese de Doutorado em Educação. Faculdade de Educação, Universidade Federal de Goiás, Goiânia.

FREIRE, S.M.; MURCE, N.(2009). O ensino e a aprendizagem de língua estrangeira: algumas questões sobre o corpo. Revista Solta a voz, v.20, pp.73-86.

FREUD, S. (1905/1996). Os chistes e sua relação com o inconsciente. Edição Standard Brasileira das Obras Psicológicas Completas de Sigmund Freud, vol. VIII, Rio de Janeiro: Imago. (1929/1996). O mal-estar na civilização. Edição Standard Brasileira das Obras Psicológicas Completas de Sigmund Freud, Vol. XXI, Rio de Janeiro: Imago.

JORDÃO, C.; MARTINEZ, J.Z.; HALU, R.C. (orgs.) (2011). Formação "desformatada" práticas com professores de língua inglesa. Campinas: Pontes.

LACAN, J. (1962-1963/2005). O Seminário, livro 10. A angústia, trad. Vera Ribeiro. Rio de Janeiro: Zahar Editor.

(1974-1975). Seminário 22, RSI. Inédito.

LEMOS, M.T.G. (2007). Desejo de Educar. Educação Temática Digital, vol.8, Junho, pp.80-89.

MOITA LOPES, L. P. (org.) (2006). Por uma Linguística Aplicada indisciplinar. São Paulo: Parábola Editorial.

MORAES, M.R.S. (1999). Materna/Estrangeira: o que Freud fez da lingua. Tese de Doutorado em Linguística. Instituto de Estudos da Linguagem, Unicamp, Campinas. . Língua materna e estrangeiridade. Revista Solta a voz, v.20, pp.65-72.

NOGUEIRA, A. L. H.; FIAD, R. S. (2007). Apropriação do "saber docente": aspectos da relação teoria e prática. In KLEIMAN, A. B.; CAVALCANTI, M.C. (orgs.) Linguística Aplicada: suas faces e interfaces. Campinas, SP: Mercado de Letras, pp. 299-316.

PORGE, E. (2009). Um sujeito sem subjetividade, trad. Viviane Veras. Literal, n.12, pp.145156.

RAJAGOPALAN, K. (2006). Repensar o papel da Linguística Aplicada. In: MOITA LOPES, L. P. (org.), Por uma Linguística Aplicada indisciplinar. São Paulo: Parábola Editorial, pp. 149-168.

REVUZ, C. (1998). A língua estrangeira entre o desejo de um outro lugar e o risco do exílio, trad. Silvana Serrani-Infante. In: Signorini, I. (org.),Lingua(gem) e identidade. Campinas, SP: Mercado de Letras; São Paulo: Fapesp, pp.213-230.

SCHMITZ, J. R. (2007). Algumas reflexões sobre o ensino de gramática em língua estrangeira: um guia prático. In KLEIMAN, A. B.; CAVALCANTI, M.C. (orgs.) 
O imperativo da aplicação na formação de professores de línguas...

Linguística Aplicada: suas faces e interfaces. Campinas, SP: Mercado de Letras, pp. 145-160.

VERAS, V. (2008). O extrangeiro na língua materna: (não) desejar as coisas alheias. Revista Solta a voz, v.19, pp.111-124.

Recebido: 05/01/2013

Aceito: 21/04/2013 
